\title{
Petites filles de la Côte
}

\author{
Olga Duhamel
}

Where we speak of the strength of little girls who stomp on scenic shores, who thread in a reality mixed with dream throughout a summer holiday.

D'ici, j'entends les bateaux du port. Tout est très calme, même les camions vont doucement, comme les bateaux. Engins puissants qui font tourner leur mécanisme ce matin du début juillet sous le soleil. J'attendais. Les chiens se sont endormis. J'ai parlé anglais toute la nuit en luttant contre le sommeil pour demander des billets de train dans toutes les gares et l'on me montrait du doigt la sortie de la ville vers les villages de la Côte, les bretelles d'autoroute hostiles à celui qui marche, l'autoroute et les immenses panneaux de direction accrochés aux poteaux recouverts de gaz carbonique qui laisse une couche de gris que ni la pluie ni le vent ne peuvent enlever. On me montrait du doigt la limite des villes où les voitures innombrables prennent de la vitesse tandis que le marcheur est saisi de découragement dans l'organisation routière qui n'est plus à son échelle. Et tout ça glisse sur l'indifférence des petites filles.

Les petites filles tournent leurs paumes, montrent leurs mains. Elles sont toutes au moins aussi futées sinon plus qu'Alice, elles crânent devant les grands lapins blancs et montrent leur poitrine encore plate dans les piscines publiques et sur les plages.

Elles regardent au-dehors.

Sur la plage, on entend leur joie sauvage d'être nues dans l'eau. On leur dit: Arrête ! Et elles se tortillent en hurlant: J'ai des os, des boyaux, de la chair et de la peau. Petits vers humains à demi nu durant l'été et qui courent sur le sable.

Le temps qui passe est comme un océan pour les petites filles qui toujours menace de les engloutir pour de bon.

Je reconstitue dans ma tête ton pas de très jeune fille. Tes fesses d'enfant de 7 ans. Les premiers baisers. Les rêves. La nourriture qui très vite devient cette chose dont on a ardemment la nostalgie. Le pain au chocolat de mon enfance, le palmier. Puis les cigarettes, les cafés et les flippers de ton adolescence. Je reviens et je tourne dans ton enfance, une noisette et dix sacs empruntés.

Le village donne sur la mer. Les bâtiments blancs, somptueux, ont été élevés sur d'anciens tracés qui obéissaient à d'autres ambitions que la rectitude. Ils ont l'onctuosité de la glace à la vanille. On peut entrer par une rue et sortir par une autre, jusqu'à la plage, jusqu'à la mer, où tous les cafés accrochent leur carte toute faite de glaces et d'esquimaux présentés de manière avantageuse sur des cartons brillants, et les enfants déchiffrent tout le rêve concentré dans ces cartons. Sans les voir, des groupes de gens passent devant ces cartons coloriés, rapidement, 
tandis que les enfants suivent, entraînés dans la marche, mais en tournant la tête, en se tordant la tête même, pour continuer le plus longtemps possible de regarder les glaces en forme de pied rose ou de vaisseau spatial.

Je reste de très longues heures à attendre une chose ou une autre. La fin de la nuit, la fin de l'après-midi, l'heure de manger etc. Les jours passent lentement durant les vacances. Je traverse la petite ville, d'un bâtiment à un autre, d'une ruelle à une autre, puis jusqu'à une placette et jusqu'à un café qui fait l'angle et même au-delà, un café que l'on peut traverser jusqu'à la plage où les enfants crient, jusqu'aux hanches dans l'eau, ou jouent au ballon dans le sable. Quelque chose tourne sur les cris des enfants qui se jettent dans les rouleaux. Les gens préparent pour les petits des goûters parce qu'ils meurent de faim à s'agiter de la sorte. Tandis qu'autour des objets scintillent de leur présence. J'ai été effrayée par le monde des amputations. Dans le journal, on peut lire qu'un requin a arraché le bras d'une enfant dans les eaux chaudes de la Floride et que l'oncle de l'enfant a tenté en vain de retrouver le bras au fond de l'eau. Il y a quelque chose en forme de fleur. Gagner une autre amplitude. Un bras a été avalé par un requin dans les eaux de la Floride. Je voudrais plonger avec toi.

Le village est comme de la glace à la vanille, très onctueuse, et ton sourire est chaud et parfait.

On était sous l'empire de cycles silencieux avec lesquels la parole entretenait une sorte de course impossible. La parole dessinait des paysages. Et des processus invisibles agitaient l'intérieur. Il y avait une mesure, une échelle humaine à hauteur de laquelle on reconnaissait les choses, et puis l'abstraction du très petit et du très grand.

Ce qui se déroulait en fin de compte fonctionnait à la manière d'une image religieuse. En bout de piste, les figures et les silhouettes prenaient des airs alanguis et symboliques. Lapin de chocolat aux yeux de sucre teints jaune, œuf de Pâques, poule en chocolat. On donne aux petites filles des poules, des lapins en chocolat avec un ruban au cou souvent et présentés dans des emballages de carton avec un côté en plastique transparent qui permet de voir l'expression neutre qu'ils arborent. On voit leurs visages inexpressifs à travers la petite vitrine de plastique. On offre aussi aux petites filles des brioches dans lesquelles on trouve des oufs entiers peints de couleur, bleu ou rose, toutes les brioches et tous les gâteaux des plus belles pâtisseries de la Méditerranée.

La mer est bordée de pins vers là-bas. Criques d'eau bleue et aiguilles de pins. Je dors peu la nuit à présent et je rattrape le sommeil sur la plage le jour, dans une forme d'hallucination étale, comme la mer d'huile au loin qui s'offre au regard au milieu du piaillement des enfants, de la musique et du va-et-vient des baigneurs. La chaleur donne un bourdonnement dans la tête. Les petites filles creusent dans le sable des trous avec leur pelle de plastique, puis s'empressent de remplir le trou d'eau salée. Et elles regardent comment tout ça bouge. L'instabilité du sable et l'instabilité de l'eau. La nuit je dors peu. Le temps passe.

Les piqûres d'insecte me font enfler et rendent toute la peau de mon ventre rouge. Toute la peau me démange, des bêtes microscopiques me dévorent la peau, elles achèvent de m'épuiser comme lorsque les enfants prennent dans 
l'épuisette les petits poissons de l'aquarium et qu'ils les replongent à moitié morts dans l'eau plusieurs minutes après avoir nettoyé les parois de l'aquarium. Souvent, un poisson saute de l'épuisette et tombe brutalement sur le sol si sec. Le sol est mortellement aride pour les poissons.

Les aquariums et les cages à oiseaux sont des parodies brutales de nos vies dans les villes et c'est pourquoi les petites filles les regardent avec tant d'attention. Elles s'instruisent.

Ma nièce et moi, nous nous sommes légèrement éloignées de la plage vers les rochers hier, pour plonger. Sur les rochers, des hommes nus avec leur sexe rouge nous dévisageaient. La mer était un peu agitée. On a plongé avec les masques, les tubas et les palmes dans les vagues pour regarder le fond de l'eau, les bancs de poissons argentés qui brillent dans la pénombre, les dorades et les girelles. Une pieuvre allait doucement contre un rocher avec ses mouvements d'organe fait pour le plaisir quand ma nièce a fiché un harpon d'enfant dans le corps de la pieuvre. L'animal allait contre le rocher et l'enfant a harponné cette muqueuse-là, plus grande qu'un organe humain. Le poulpe a jeté son encre. Et l'enfant un peu dégoûtée a débarrassé son jouet du cadavre mou de la pieuvre.

Au bord de la plage, la nuit, des adolescents ont mis leur sexe à tour de rôle contre un poulpe mort.

À nouveau maintenant les palmiers, les pins parasols, les lauriers blancs submergent.

Aujourd'hui, des gens se baignent en silence dans la piscine sous le soleil de midi, loin du bruit de la plage. Mais les cigales empêchent d'entendre la porte tout au bout de la villa, elles empêchent aussi d'entendre ce que chuchotent les petites filles au fond du jardin. Les petites filles parlent bas et font des signes avec les mains.

Est-ce que les paysages des rêves coïncident avec le monde éveillé?

Lentement, ils se rencontrent, se fondent, comme la glace à la vanille et la glace au chocolat fondent et se mêlent au fond des coupes. 